\title{
Tick Paralysis in a Snowshoe Hare by Ixodes pacificus Ticks in British Columbia, Canada
}

Keywords: Snowshoe hare; Lepus a meric a nus; Tick paralysis; Ixodes pacificus; Mammalian; Hosts; Ticks; Borrelia burgdorfen, PCR, Canada

\begin{abstract}
We provide the first reported case of tick paralysis in a wildlife animal caused by the westem blacklegged tick, Ixodes pacificus Cooley \& Kohls. Six I. pacificus females and one male were collected from a feral Snowshoe Hare roaming the coastal area of southwestern British Columbia, Canada. When the hare was rescued from the forest habitat, it was unable to walk, and showed typical symptoms of tick paralysis, including ascending flaccid paralysis. At the nearby wildlife rehabilitation centre, engorged I. pacificus females were collected from the hare. Because of the rapid progress of tick paralysis, the Snowshoe Hare, Lepus a meric a nus Erxleben, died shortly after the start of rehabilitation. X-rays were normal, and reveal no physical injury. Since the Lyme disease spirochete, Borrelia burgdorferi sensu lato (s.l) J ohnson, Schmid, Hyde, Steigerwalt, and Brenner, was circulating enzootically in this area, we tested all ticks infesting the Snowshoe Hare. Using PCR, a single male was positive for B. burgdorferi s.l., whereas all of the attached $I$. pacificus females were negative. Since only the single I. pacificus male was infected with Lyme disease spirochetes, we intuitively conclude that the engorged $I$. pacificus females were the cause of tick paralysis. Medical practitioners and wildlife rehabilitators are advised to consider tick paralysis in their differential diagnosis when people, livestock, companion animals, and wildlife animals present with acute ascending motor deficits after exposure in grassy and wooded areas.
\end{abstract}

\section{Introduction}

Tick paralysis occurs when certain tick species secrete neurotoxins into a host, and cause a disabling or lethal condition [1]. This paralyzing syndrome typically happens after 5-7 days of tick feeding; however, disruption of motor coordination can start within 4 days and escalate to day 8 [2]. Symptoms of tick paralysis are characterized by ascending flaccid paralysis starting in the hind quarters, and moving forward. An unsteady gait normally marks the onset of paralysis in mammals, especially in the hind legs. Symptoms of a lesser nature may include general malaise, lethargy, muscular weakness, ataxia, and loss of appetite. In particular, the hind limbs lose strength and coordination. As well, early symptoms usually reduce ankle, knee, and abdominal reflexes [1]. Paralysis of the chest muscle will soon lead to motor incoordination and respiratory failure. Humans lose coordination, and frequently show difficulties in speech, breathing, chewing, swallowing, and perhaps have a headache or incur vomiting. If ticks are not removal or released upon repletion, the paralysis will progress, and cause death. Early recognition of the engorging tick and the removal of it are paramount to halt and reverse neuromotor paralysis. Tick salivary neurotoxins impede the activity of acetyl cholinesterase that allows the acetylcholine to normally conduct impulses between nerve endings and, subsequently, induce a marked reduction of motor nerve conduction. Patients normally recover when ticks are removed. Early research has failed to show any causal organism associated with tick paralysis [2].

\section{Journal of}

Veterinary Science \& Medicine

\author{
John D Scott ${ }^{1 *}$, Catherine M Scott ${ }^{1}$ and John F \\ Anderson ${ }^{2}$ \\ ${ }^{1}$ Research Division, Lyme Ontario, Fergus, Ontario, Canada \\ ${ }^{2}$ Department of Entomology and Center for Vector Ecology and \\ Zoonotic Diseases. The Connecticut Agricultural Experiment \\ Station, New Haven, USA

\section{Address for Correspondence} \\ John D Scott, Research Division, Lyme Ontario, 365 St. David St. South, \\ Fergus, Ontario, Canada N1M 2L7; Email: jkscott@bserv.com \\ Copyright: (C) 2014 Scott JD, et al. This is an open access article \\ distributed under the Creative Commons Attribution License, which \\ permits unrestricted use, distribution, and reproduction in any medium, \\ provided the original work is properly cited. \\ Submission: 18 August 2014 \\ Accepted: 26 August 2014 \\ Published: 29 August 2014
}

Globally, at least 43 species of ticks in 10 genera cause tick paralysis in humans, pets, livestock, and wildlife animals, including birds [3]. The bird-associated tick, Ixodes brunneus Koch (Ixodida: Ixodidae), which feeds exclusively on birds, particularly migratory species [4], can cause avian tick paralysis [5]. Most often tick paralysis is caused by female ticks; however, nymphs of the Karoo paralysis tick, Ixodes rubicundus Neumann paralysed rabbits in South Africa [6]. Alternatively, larvae of the bird-feeding argasid (soft-bodied) tick, Argas walkerae Kaiser \& Hoogstraal cause tick paralysis in chickens in the southern part of Africa. Experiments with the Rocky Mountain wood tick, Dermacentor andersoni Stiles, indicate that females are most toxic when feeding prior to mating, but little evidence is known about the effect of timing of mating in other ixodid (hard-bodied) tick species [2]. The number of feeding ticks and, likewise, the tick species, have a bearing on toxicity. For example, in Australia, a single Australian paralysis tick, Ixodes holocyclus Neumann can paralyse and kill a cow. For patients paralysed by this tick species, recovery is prolonged, and often lasts days to weeks.

Historically, tick paralysis was first noted in 1824 along the eastern coastal strip of Australia where I. holocyclus is indigenous [7]. Later, tick paralysis was observed in sheep in South Africa in 1890 [8]. In North America, the earliest reported cases occurred in 1898 in Oregon and Idaho [9] and, subsequently, studied and documented in British Columbia [10]. For the later cases, D. andersoni was thoroughly studied in livestock and wildlife animals, and shown to be the predominant species causing paralysis in North America. Tick paralysis has also been documented in Eurasia in widely scattered areas. In India, Singh [11] recorded tick paralysis in rabbits that was initiated by Haemaphysalis kutchensis Hoogstraal and Trapido. This tick species causes lethargy, weakness, and rigid paralysis of limbs in rabbits [11]. Pertinent to our study, Nelson [12] provides the first documentation of the western blacklegged tick, Ixodes pacificus Cooley and Kohls, causing tick paralysis in a vertebrate host. Two days after an outing in California, a pet owner found that her dog was unable to get out of its box because its hind quarters would not carry its weight. After a diligent search, the owner found an attached 
tick. Within two hours after tick removal, the dog was able to walk. The tick was later identified as a partially engorged I. pacificus female. Additionally, Lane et al. [13] reported a case of tick paralysis in a dog parasitized by two I. pacificus females.

Pertinent to our study, I. pacificus is a competent vector of the Lyme disease spirochete, Borrelia burgdorferi sensu lato (s.l.) Johnson, Schmid, Hyde, Steigerwalt, and Brenner. Because B. burgdorferi s.l. had previously been detected in ticks collected in the area [14], we employed PCR testing on all ticks infesting the hare. As well, we conducted post-mortem surgery to determine if this spirochetal pathogen was present in body tissues. Overall, we assessed several possible causes of death.

\section{Materials and Methods}

A feral Snowshoe Hare, Lepus amerianus Erxleben, was recovered $3 \mathrm{~km}$ northeast of Sechelt, British Columbia. This remote coastal site is a logged, second-growth rainforest consisting of deciduous and coniferous trees with intermittent low-dense bushes. This elevated site has a well-drained, light-textured soil near a gravel pit. On 16 March 2014, a local hiker happened upon a febrile hare lying prostrate on the forest floor with its hind legs splayed out behind. It was observed briefly, and it was evident from the vegetative debris on its fur that this adult male had been rolling, and trying to be ambulatory. Because the hare appeared lame, and had great difficulty trying to walk, the rescuers placed it in a coat, and took it to the Gibsons Wildlife Rehabilitation Centre. Upon physical examination, the hare was lame, lying still, lethargic, and unable to stand, but had occasional movement in the hind legs. It appeared not to have any physical injury. Staff used fine-pointed stainless steel tweezers to remove 5 engorged ticks from the left side of the neck. These ticks were put in a clear 4 dram $(12 \mathrm{~mL})$ polystyrene vial with a white polypropylene cap vented with tulle netting. This container was placed in a ziplock plastic bag with slightly moisten paper towel. For nutritional support, an apple was given to the Snowshoe Hare; however, it would not eat. The hare was placed in a warm kennel cab, and darkened. Within 30 minutes, it died. The hare was promptly put in the freezer, and later taken to the local veterinarian for lateral and dorsal $\mathrm{x}$-rays. Several tissues from various parts of the body were surgically removed, and sent to IDEXX Laboratories, Markham, Ontario for PCR testing.

The ticks were promptly sent by express mail for positive identification. At the tick identification laboratory (JDS), one $I$. pacificus male was found mating with one of the live, engorged females. Later, a sixth engorged I. pacificus female, which was initially overlooked in the long hair, was found on the neck of the hare during post-mortem examination. After confirmation of identification, all 7 I. pacificus ticks were sent by overnight courier to the PCR amplification research laboratory (JFA) to detect B. burgdorferi s.l. These ticks were tested using methods previous described $[15,16]$, and modified to employ current commercial products and in-house techniques [17].

\section{Results}

\section{Snowshoe hare}

When the Snowshoe Hare was found in the upland rainforest, it was prostrate, and had its hind legs splayed posterior. The debris on its fur indicated that it had been rolling on the forest floor (Figure 1).

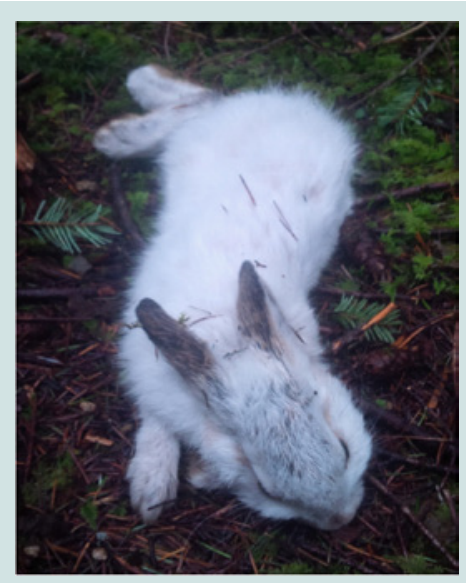

Figure 1: The feral Snowshoe Hare exhibits signs and symptoms of tick paralysis. The debris on the fur indicates that it was rolling, and the hind legs splayed behind reveal paralysis in the hind quarters. Photo credits: William McDonagh.

The hare exhibited motor in coordination, ataxia, and flaccid paresis in its extremities, especially its hind quarters (Figure 1). The lateral and dorsal $\mathrm{x}$-rays of the hare were normal, and revealed no evidence of spinal cord trauma or physical injury (Figure 2A and Figure 2B). All of the eleven anatomical tissues, which were surgically removed post-mortem, were negative by PCR for B. burgdorferi s.l. (Table 1).

\section{Ticks collected}

In total, seven $I$. pacificus adults (6 engorged females, 1 male) were collected from the Snowshoe Hare. Based on the extent of engorgement (partial to fully engorged), it was estimated that the six females had been feeding 4-7 days. Since these six females were directly attached to the hare, they were incriminated in the etiology of tick paralysis. Of note, an I. pacificus male was discovered mating with one of the six attached females, which indicates an established population of I. pacificus in this locality.

\section{Spirochete detection}

All of the six I. pacificus females, which were detached from the hare, were negative by PCR for B. burgdorferi s.l. In contrast, the single I. pacificus male, which was mating with one of the females, was positive by PCR for B. burgdorferi s.l. Although the unattached I. pacificus male revealed positivity for Lyme disease spirochetes, it would neither play a role in potential transfer of borrelial spirochetes nor the demise of the hare.

\section{Discussion}

We document the first report of tick paralysis in a Snowshoe Hare caused by I. pacificus. After a thorough search of the scientific literature, we were unable to find a case of tick paralysis in a wildlife animal caused by I. pacificus. This case of tick paralysis was typical of other cases by other tick researchers in North America [2]. In their study, marmots were easily paralysed by $D$. andersoni females indigenous to central British Columbia. Similar to the findings in this in-depth study, the Snowshoe Hare was found in a weaken state on the forest floor with its hind legs splayed posterior. Like other wildlife 


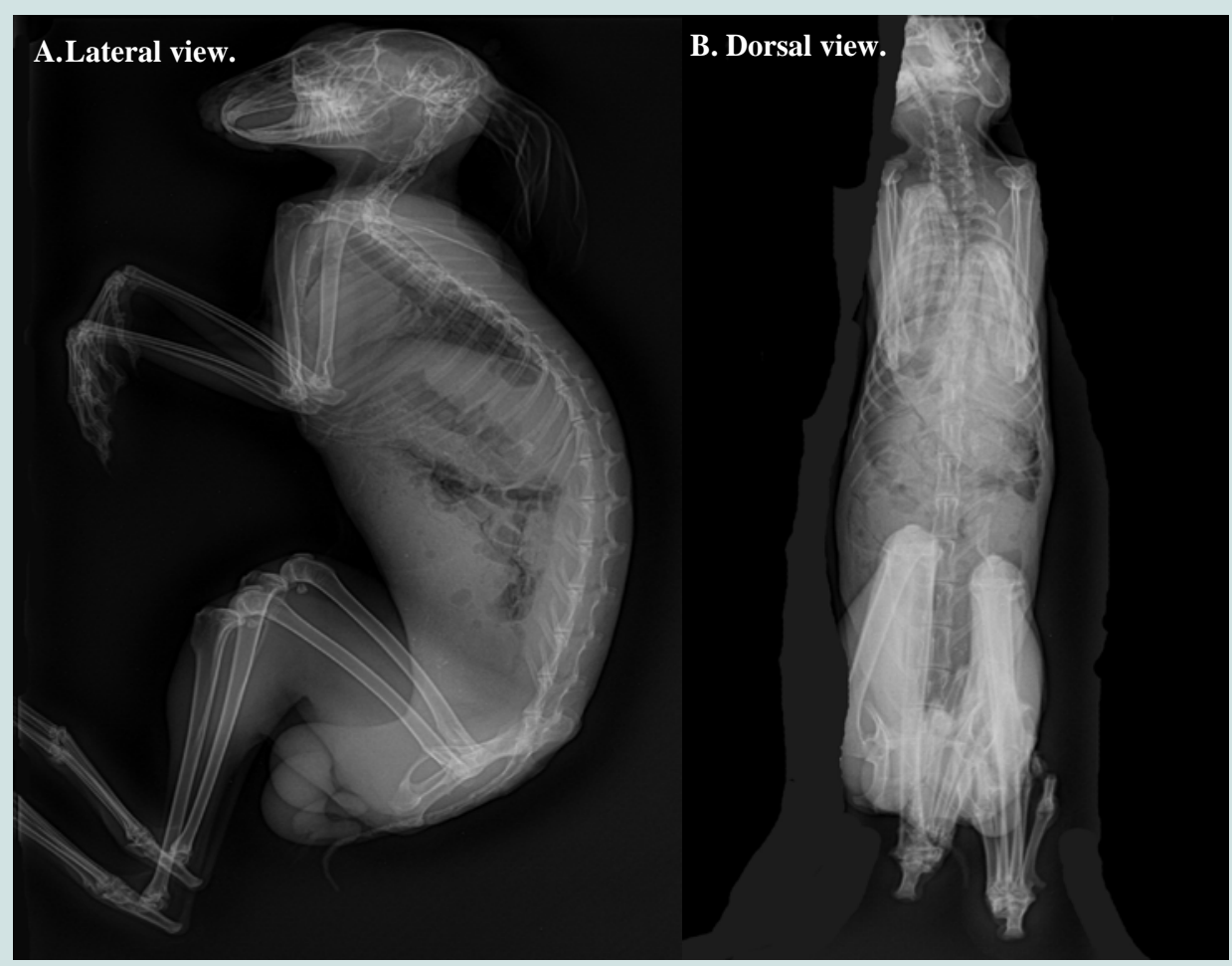

Figure 2: Post-mortem x-rays of Snowshoe Hare reveals no physical injury.

and domestic mammals parasitized by paralysis-causing ticks, it had great difficulty walking. When found in the forest, it had been rolling in order to try to move and be ambulatory. It would not eat when offered food. The tick paralysis had advanced to the point that it died shortly after capture.

In North America, at least 5 tick species cause tick paralysis. The Rocky Mountain wood tick, $D$. andersoni, which is native to the Pacific Northwest, induces paralysis in humans, livestock, and wildlife animals [2]. During early studies, the fatality rate was $10 \%$ in human cases. In northeastern and north-central North America [1] and coastal California [13], the American dog tick, Dermacentor variabilis (Say), causes tick paralysis in humans and dogs. The Pacific Coast tick, Dermacentor occidentalus Marx, established in western United States, has been reported to cause paralysis in livestock and wild animals [1]. Other tick species are known to cause paralysis in dogs, including the Gulf Coast tick, Amblyomma maculatum Koch and the blacklegged tick, Ixodes scapularis Say, and the western blacklegged tick, I. pacificus $[1,18]$.

Based on the wide dispersal of ticks by songbirds [19], and the presence of Lyme disease in this West Coast bioregion [14], we tested the Snowshoe Hare for B. burgdorferi s.l. Since this tick-borne spirochetosis can cause death in humans [20-22] and domestic animals [23], we conducted PCR testing on the Snowshoe Hare for $B$. burgdorferi s.l. In addition, Anderson et al. [25] isolated B. burgdorferi s.l. from Eastern Cottontail rabbits (J. A. Allen), which act as reservoir hosts. Since all eleven tissues from the Snowshoe Hare in our study were negative for B. burgdorferi s.l., we ruled out Lyme disease as the cause of death.
Another potentially fatal disease, tularemia, which is caused by the bacterium, Francisella tularensis McCoy and Chapin, was also considered as a possible cause of death [26]. This epizootic occurs in lagomorphs, and is known to be transmitted by water-borne and tick-borne routes. Even though the Snowshoe Hare was very slow to move and lacked fear of people, tularema was discounted from the differential diagnosis on the basis that the hare had pronounced, ascending symmetrical paralysis. Moreover, the hare did not have other typical symptoms of tularemia, such as rubbing its nose and displaying muscle spasms. The internal organs looked healthy, and there was no pathological evidence of white spots on the liver, which normally indicate tularemia infection. Certain tick species transmit this zoonotic pathogen, especially Haemaphysalis leporispalustris Packard, D. variabilis, D. andersoni, and Amblyomma americanum (L.) [1]. Of these tick species, only $H$. leporispalustris would be questing at this time of year in this vicinity, and none were observed on the hare.

Chagnon et al. [27] documented tick paralysis in a 4-year-old girl in West Virginia. The girl became febrile, and had weakness in lower extremities, unsteady gait, and was hospitalized. As symptoms advanced, she developed respiratory distress, flaccid paralysis in all 4 extremities, bifacial weakness, and complete aflexia. Nine days after symptoms started, a $3-\mathrm{cm}$, fully engorged $D$. variabilis female was removed from her hair. After 6 days, the girl was able to walk well, and had regained her facial strength.

Certain lizards are know to have a borrelicidal effect on $B$. burgdorferi s.l. in blood-feeding ticks. In this area, Northwestern Alligator Lizards, Elgaria coerulea (Wiegmann) act as hosts of $I$. pacificus larvae and nymphs. In this study, the low infection rate of 
Citation: Scott JD, Scott CM, Anderson JF. Tick Paralysis in a Snowshoe Hare by Ixodes pacificus Ticks in British Columbia, Canada. J Veter Sci Med. 2014;2(2): 5 .

Table 1: PCR testing for Borrelia burgdorferi s.l. on tissues collected from the Snowshoe Hare

\begin{tabular}{|c|c|}
\hline Body tissues & Results, PCR-Bb \\
\hline Bladder & negative \\
\hline $\begin{array}{l}\text { Brain: hypothalamus } \\
\text { periventicular white matter }\end{array}$ & $\begin{array}{l}\text { negative } \\
\text { negative }\end{array}$ \\
\hline Skin, neck, left, over carotid artery & negative \\
\hline $\begin{array}{l}\text { Synovium: femur-tibia joint, right } \\
\text { femur-tibia joint, left } \\
\text { humerus-radius joint, right }\end{array}$ & $\begin{array}{l}\text { negative } \\
\text { negative } \\
\text { negative }\end{array}$ \\
\hline $\begin{array}{l}\text { Bone marrow: femur, right } \\
\text { femur, left } \\
\text { humerus, right } \\
\text { humerus, left }\end{array}$ & $\begin{array}{l}\text { negative } \\
\text { negative } \\
\text { negative } \\
\text { negative }\end{array}$ \\
\hline
\end{tabular}

PCR-Bb, presence of B. burgdorferi s.l. using PCR.

B. burgdorferi s.l. was likely caused by borrelicidal activity of a heatlabile, spirochete-killing factor in the blood of these reptilian hosts.

Tick paralysis can lead to significant morbidity and, if not detected, cause mortality. The typical syndrome is characterized as an ascending, symmetrical flaccid tetraplegia with functional impediments to the reflexes of the tendons of the limbs and abdomen. In humans, difficulties arise in speech, breathing, chewing, and swallowing [3]. The paralysis is caused by neurotoxins from the salivary glands of the ticks during the blood meal. These neurotoxins are believed to decrease presynaptic acetylcholine release at the nerve synapse, similar to botulinum toxin. The paralysis can last for hours or days. As well, Rose and Gregson [28] showed that during tick paralysis blockage occurred at myoneural junctions and spinal cord synapses because decreased liberation or synthesis of actylcholine occurs at the nerve endings. Apparently, tick neurotoxins cause a physiological defect in the motor nerve fibres, and the ability of the nerve impulse to transverse along nerve fibres. Esplin et al. [29] observed that the stretch reflexes of the paralysed animal were absent and; therefore, tick paralysis may be attributed to impairment of the monosynaptic pathways by blockage of the fine terminal nerve fibres. Not only do I. pacificus neurotoxins inhibit cholinesterase function, they interfere with the ability of acetycholine to conduct electrical impulses between nerve endings. Inevitably, in the advanced stage of tick paralysis, the diaphragm muscles halt, and the victim succumbs.

Using D. andersoni females, Gregson [2] speculated that rabbits are resistant to tick paralysis. In contrast, we show that Snowshoe Hares are susceptible to tick paralysis by I. pacificus. Additionally, Spickett et al. [6] reported tick paralysis in rabbits by I. rubicundus nymphs in South Africa. Tick paralysis often starts on the fourth day after tick attachment, but usually begins after a feeding interval of 5-7 days. It is reversible on removal of the tick. Pursuant to pathogenesis, paralysis is accelerated by several ticks feeding simultaneously on the host.

In nature, tick paralysis is a subtle way that ticks immobilize their hosts and; there by, sustain the species. Ticks carefully select the attachment site on their hosts. The feeding location is normally over a blood vessel and, also, in a non-groomed part of the body. In this study, the six engorged I. pacificus females were attached directly over the carotid artery approximately $4 \mathrm{~cm}$ posterior to the base of the left ear. At this particular cutaneous feeding site, Snowshoe Hares can neither groom nor shake partially or fully engorged ticks from their bodies. From an innately-selected feeding site, such as the carotid artery, spirochetes and tick-borne pathogens can move quickly to the brain and other parts of the body, and shut down vital body function. In essence, tick paralysis is an inherent mechanism for ixodid ectoparasites to safeguard themselves during a blood meal, especially fully engorged $I$. pacificus females.

A typical case of tick paralysis in humans will exacerbate as tick feeding progresses. The patient starts to experience symptoms within 4-6 days after tick attachment, and loses coordination, experiences difficulty in walking, and has unsteadiness in gait. The condition progresses to ataxia, accompanied by numbness of extremities. Within 24 hours, the patient becomes completely paralysed, unable to move legs, arms or sit up. Difficulty of speech occurs, and finally, respiratory failure and death [2]. This scenario of tick paralysis in humans coincides with our case in the Snowshoe Hare, and substantiates the putative potency of tick neurotoxins. The tick neurotoxins often affect bulbar and medulla oblongata function that deals with vital functions, such as circulation and special senses. As the symptoms progress in livestock, the animals often experience lack of coordination and fall frequently [2]. Animals are unable to raise their heads, and often roll into a gully or stream. In our study, the Snowshoe Hare had been rolling in the leaf litter as evident by the debris on its fur, and had paralysis in its hind legs. Complete paralysis and death follow promptly. Not only will certain tick species cause tick paralysis, heavy infestations will accelerate the paralyzing process.

In summary, I. pacificus females will induce tick paralysis in Snowshoe Hares, and cause death. Tick neurotoxins interfere with the conductivity of electrical impulses between nerve endings, and progressively paralyse lagomorphs. In this study, the Snowshoe Hare had no physical injury, but exhibited motor incoordination and ascending motor paralysis. When patients have lower limb weakness and unsteady gait, diligent health-care providers, veterinarians, and wildlife rehabilitation workers must carefully check shaded areas of the body, and palpate the hair and fur, especially on the head and neck, for the presence of attached ticks. Even though acaricides currently help to reduce the incidence of tick paralysis in companion animals and pastured livestock, unprotected outdoors people and wildlife animals will be vulnerable to questing ticks. Any ticks found should be carefully removed with fine-pointed, stainless steel tweezers, and saved for positive identification. Medical and rehabilitation teams must consider tick paralysis whenever their patients have ascending flaccid paralysis and have had recent outdoor exposure in grassy and wooded areas.

\section{References}

1. Sonenshine DE (1993) Ticks-borne and tick-caused diseases: Biology of Ticks, Vol. 2, Oxford University Press, New York, Oxford.

2. Gregson JD (1973) Tick paralysis. An appraisal of natural and experimenta data. Canada Department of Agriculture. Monograph No. 9.

3. Gothe R, Kunze K, Hoogstraal H (1979) The mechanisms of pathogenicity in the tick paralyses. J Med Entomol 16: 357-369.

4. Durden LA, Keirans JE (1996) Nymphs of the genus Ixodes (Acari: Ixodidae) of the United States: taxonomy, identification key, distribution, hosts, and medical/veterinary importance. Thomas Say Publications in Entomology. Entomological Society of America, Lanham, MD. 
Citation: Scott JD, Scott CM, Anderson JF. Tick Paralysis in a Snowshoe Hare by Ixodes pacificus Ticks in British Columbia, Canada. J Veter Sci Med. 2014;2(2): 5 .

ISSN: $2325-4645$

5. Luttrell MP, Creekmore LH, Mertins JW (1996) Avian tick paralysis caused by Ixodes brunneus in the southeastern United States. J Wildl Dis 32: 133-136.

6. Spickett AM, Elliott EGR, Heyne H, Neser JA (1989) Paralysis of laboratory rabbits by nymphae of Ixodes rubicundus Neumann 1904 (Acarina: Ixodidae) and some effects on the life-cycle following feeding under different temperature conditions. Onderstepoort J Vet Res 56: 59-62.

7. Scott E (1921) Hume and Hovell's journey to Port Phillip. Roy Aust Hist Soc VII: 289-380.

8. Neitz WO (1962) The different forms of tick toxicosis: a review. $2^{\text {nd }}$ meeting FAO/OIE expert panel on tick-borne diseases of livestock. Cairo, U.A.R.

9. Standbury JB, Huyck JH (1945) Tick paralysis: a critical review. Medicine (Baltimore) 24: 219-242.

10. Todd JL (1912) Tick bite in British Columbia. Can Med Assoc J 2: 1118-1119.

11. Singh KRP (1963) A note on tick paralysis in rabbits. Curr Sci 32: 116

12. Nelson BC (1973) California Vector Views 20: 80-82.

13. Lane RS, Peek J, Donaghey PJ (1984) Tick (Acarii: Ixodidae) paralysis in dogs from northern California: acarological and clinical findings. J Med Entomol 21: 321-326.

14. Banerjee SN, Banerjee M, Smith JA, Fernando K (1994) Lyme disease in British Columbia - an update. Proceedings of the VII Annual Lyme Disease Foundation International Conference.

15. Persing DH, Telford SR, Spielman AS, Barthold SW (1990) Detection of Borrelia burgdorferi infection in Ixodes dammini ticks with the polymerase chain reaction. J Clin Microbiol 28: 566-572.

16. Persing DH, Telford SR, Rys PN, Dodge DE, White TJ, et al. (1990) Detection of Borrelia burgdorferi DNA in museum specimens of Ixodes dammini ticks. Science 249: 1420-1423.

17. Scott JD, Anderson JF, Durden LA (2013) First detection of Lyme disease spirochete Borrelia burgdorferi in ticks collected from a raptor in Canada. $\mathrm{J}$ Vet Sci Med Diagn 2:4.
18. Lane RS (1984) Tick paralysis: an underreported disease of dogs in California. California Veterinarian 4: 14-16.

19. Scott JD, Anderson JF, Durden LA (2012) Widespread dispersal of Borrelia burgdorferi-infected ticks collected from songbirds across Canada. J Parasitol 98: 49-59.

20. Liegner KB, Duray P, Agricola M, Rosenkilde C, Yannuzzi LA, et al. (1997) Lyme disease and the clinical spectrum of antibiotic responsive chronic meningoencephalomyelitides. J Spir Tick Borne Dis 14: 61-73.

21. Centers for Disease Control and Prevention (CDC). (2013) Three sudden cardiac deaths associated with Lyme carditis-United States, November 2012 July 2013. MMWR Morb Mortal Wkly Rep 62: 993-996.

22. Oksi J, Kalimo H, Marttila RJ, Marjamäki M, Sonninen P, et al. (1996) Inflammatory brain changes in Lyme borreliosis: a report on three patients and review of literature. Brain 119: 2143-2154.

23. Levy SA, Duray PH (1988) Complete heart block in a dog seropositive for Borrelia burgdorferi: similarity to human Lyme carditis. J Vet Intern Med 2: 138-44.

24. James FM, Engiles JB, Beech J (2010) Meningitis, cranial neuritis, and radiculoneuritis associated with Borrelia burgdorferi infection in a horse. J Am Vet Med Assoc 237: 1180-1185.

25. Anderson JF, Magnarelli LA, LeFebvre RB, Andreadis TG, McAninch JB, et al. (1989) Antigenically variable Borrelia burgdorferi isolated from cottontail rabbits and Ixodes dentatus in rural and urban areas. J Clin Microbiol 27: 1320.

26. Dodds DG, Mackiewicz JS (1961) Some parasites and diseases of snowshoe hares in Newfoundland. J Wildlife Management 25: 409-414.

27. Chagnon SL, Naik M, Abdel-Hamid H (2014) Child neurology: tick paralysis: a diagnosis not to miss. Neurology 82: e91-e93.

28. Rose I, Gregson JD (1956) Evidence of a neuromuscular block in tick paralysis. Nature 178: 95-96.

29. Esplin DW, Philip CB, Hughes LE (1960) Impairment of muscle stretch reflexes in tick paralysis. Science 132: 958-959.

\section{Acknowledgements}

We thank Elizabeth E. Alves for her technical assistance. We are grateful to Lance A. Durden and Janet L. H. Sperling for special historical library searches. We are indebted to John Ward for computer graphics on photographs. We greatly appreciate Mike Tigchelar, Sechelt Animal Hospital, for conducting x-rays, and Clint and Irene Davy, Gibsons Wildlife Rehabilitation Centre, for rehabilitation care. Funding for this scientific study was supported in part by the Canadian Lyme Disease Foundation and the Lyme Ontario. 